\title{
Study of Energy Losses in Digital Hydraulic Multi-Pressure Actuator
}

\author{
Mikko Huova, Arttu Aalto, Matti Linjama and Kalevi Huhtala \\ Laboratory of Automation and Hydraulic engineering, Tampere University of Technology, Tampere, Finland \\ E-mail: mikko.huova@tut.fi, aalto.arttu90@gmail.com, matti.linjama@tut.fi, kalevi.huhtala@tut.fi
}

\begin{abstract}
A digital hydraulic multi-pressure actuator is a new actuator concept, which aims at lowering energy losses and decreasing dynamic requirements of a prime mover in mobile hydraulic applications. The actuator consists of an integrated hydraulic accumulator, which serves as an energy storage and a number of asymmetric cylinders acting as discrete pressure transformers. Leak-free on/off-valves are used to direct flow from the discrete pressure transformers to the actuator. Input power is supplied by charging the local accumulator with a small fixed displacement pump. Thus, the actuator requires only mean input power, while the output power peaks can be multifold. This paper concentrates on studying the controllability of the actuator concept and analyses the power losses and their sources through experimental study. The energy losses of the concept are measured in a mobile hydraulic boom mock-up and compared to earlier measured losses of a load sensing proportional valve based system. The measurements show that up to $77 \%$ of the losses can be avoided by using the new concept. Three controller types are studied numerically and experimentally and their effect on control resolution and energy efficiency is evaluated.
\end{abstract}

Keywords: Digital hydraulics, Integrated actuator, Multi-pressure system

\section{Introduction}

Hydraulic systems are used in mobile machines because they enable good power to weight ratio and generation of big forces. There are, however, few well-known downsides in the use of traditional valve-controlled hydraulic systems such as low efficiency in many operation points. Furthermore, the input power of the hydraulic supply unit is directly coupled to the output power of the actuators. In many mobile machines, the supply pump is driven by a diesel engine, which results in a system, where the diesel engine is frequently driven in a bad operating point. Furthermore, the operating point of the engine is often rapidly changing due to the changing actuator demands. This results in excessive fuel consumption and emissions [1].

The reduction of power losses in hydraulic actuators and their control valves is often important when improvement to the overall efficiency of a mobile machine is sought after. Although only a part of the total power loss occurs in the control valves, it is worth to note that also this lost hydraulic power needs to be generated by a diesel engine driven pump. They both generate considerable amount of power loss while producing the excess hydraulic power to be lost in the control valves.

To avoid above-mentioned problems, different types of hybrid mobile machines are studied. One such system is
STEAM, which consists of two accumulators maintaining two separate pressure levels utilized by the control valves of an excavator [2]. Another example of a hydraulic hybrid system used in a mobile machine is the Liebherr Pactronic ${ }^{\circledR}$ system, where an accumulator is used to store energy during load lowering to be utilized during peak loading [3]. There are steps taken towards utilization of hydraulic hybrids also in forest machinery, where an example system consists of a hydraulic accumulator which energy can be fed to a working hydraulics of a cut-to-length forest harvester via a diesel driven pump/motor [4]. Other methods improving the energy efficiency of cylinder drives include both analogue and digital hydraulic transformers [5, 6, 7] and pump controlled systems [8].

This paper studies a hydraulic hybrid actuator, which includes a hydraulic cylinder, control valves, a local energy storage and a discrete pressure converter. Figure 1 presents a simplified hydraulic diagram of the system studied. The digital hydraulic multi-pressure actuator consists of highpressure supply line HP, pressurized tank line LP and, in this example, two medium pressure lines generated by the converter cylinders. The idea of the concept was presented in [9] and the first measurement result in [10] and this paper studies the concept further through experimental measurements.

The system shares some of the operational principles with the digital hydraulic transformer $[11,12]$. In this case, there is a 
number of different pressure levels available at all times. The controller structure is based on secondary control scheme of a multi-chamber cylinder [13] and in the core of the controller structure is a discrete force controller, which tracks the force reference given to the actuator. The actuator is controlled by directing optimal pressure level to piston side chamber A and to rod side chamber $\mathrm{B}$ via the on/off-valves to generate desired actuator force. In this example, there are sixteen different pressure combinations to select from. The inflowside pressure source is discharged, while the outflow-side pressure source is charged simultaneously. It is worth to note that the small converter cylinders have limited fluid volumes and therefore it is crucial that the control system tracks the capacity (piston position) of the converter cylinders and prefers control combinations, which tend to return the converter pistons to the middle positions.

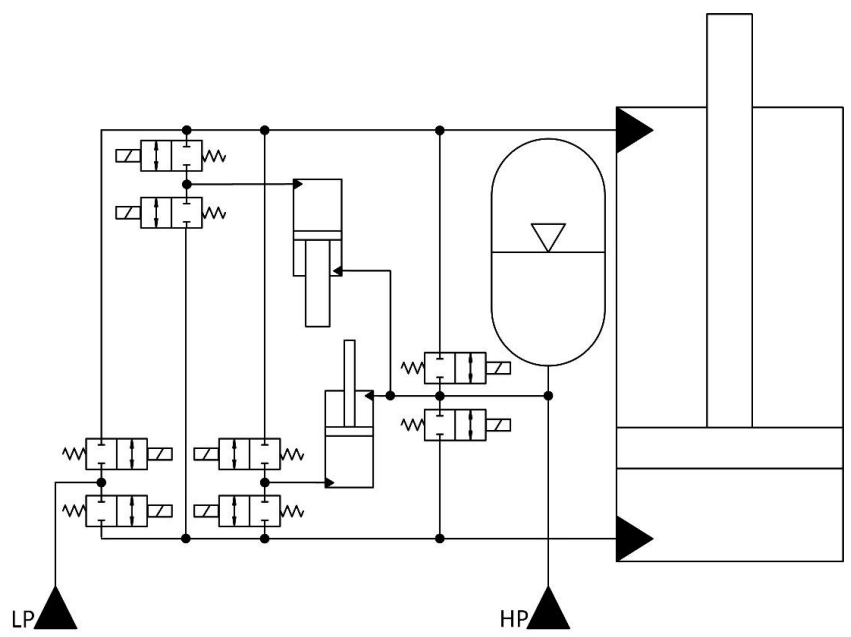

Figure 1: Simplified hydraulic diagram of a digital hydraulic multi-pressure actuator with four pressure levels

This paper studies the controllability and energy efficiency of the concept. There are three different control algorithms developed and their effect on controllability is studied numerically and experimentally. Energy efficiency is studied experimentally in a trajectory tracking application. Furthermore, the sources of the power losses are investigated in separate measurements where the pressure losses of the converter circuit are investigated in more detail.

\section{Controller design}

Figure 2 presents the upper-level block diagram of the control system.

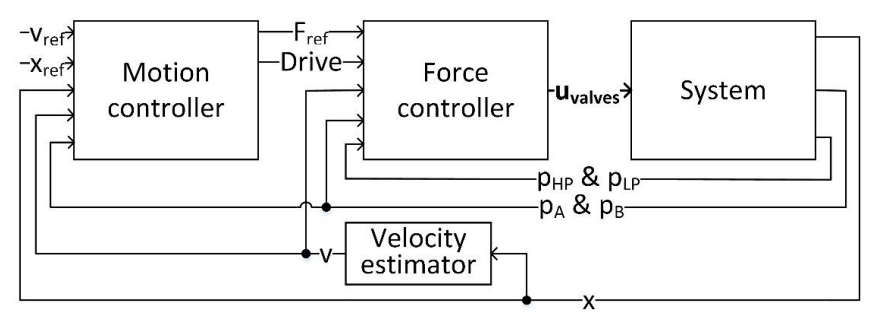

Figure 2: Block diagram of the control system
The digital hydraulic multi-pressure actuator is essentially a force generating device as all hydraulic cylinder actuators. In this case the on/off-valves are controlled such that the output force of the cylinder tracks the force reference. However, position tracking is desired in the test system and thus the motion controller forms the outer control loop as presented in fig. 2.

\subsection{Motion control}

The motion controller is designed based on the PI-type controller presented in [13]. The motion controller calculates an internal velocity reference signal $v_{\text {ref_c }}$ using the sum of PItype position controller output and the velocity of the target trajectory $v_{\text {ref. }}$ PD-type velocity controller takes $v_{\text {ref_c }}$ and the estimated velocity $v$ as inputs and outputs the force reference $F_{\text {ref. }}$ The velocity is estimated from the position measurement using a first order low pass filter and filtered discrete time derivative:

$$
\begin{aligned}
& \dot{y}(t)=\frac{1}{35 \Delta}[5 y(t)+3 y(t-\Delta)+y(t-2 \Delta) \\
& -y(t-3 \Delta)-3 y(t-4 \Delta) \\
& -5 y(t-5 \Delta)]
\end{aligned}
$$

where $\Delta$ is the sample time. Stopping and starting of the motion is handled by the motion controller. The controller uses position and velocity thresholds to calculate the Boolean signal Drive. While the Drive is true, the force controller outputs its on/off-valve command signals to the valves; otherwise the valves remain closed. The chamber pressure measurements $p_{\mathrm{A}} \& p_{\mathrm{B}}$ are input to the motion controller and they are used to reset the I-term of the PI-type position controller at the beginning of the motion. The I-term is set to match the current load force estimated from the chamber pressures.

\subsection{Basic force controller}

The force controller tracks the force reference and takes care of utilizing the medium pressure supplies such that the converter cylinders are not driven to cylinder ends. The basic version of the controller selects an optimal pressure supply for piston and piston rod side of the actuator and opens the flow path of the corresponding pressure supply. There are two parallel connected on/off-valves in each flow path in the experimental test system (in contrast to the simplified circuit in fig. 1), and they are both opened simultaneously to decrease the pressure drop. Therefore, there are $N_{\mathrm{p}}{ }^{2}$ possible control combinations to select from, where $N_{\mathrm{p}}$ is the number of supply pressure levels. The pressure drop across the on/offvalves has a significant effect on the force of the actuator. The controller models the pressure drop by assuming that the piston velocity corresponds the velocity reference. Dynamic effects are neglected and thus the actuator flow rates are:

$$
Q_{A}=v_{r e f} A_{A} ; \quad Q_{B}=-v_{r e f} A_{B}
$$

Where $A_{\mathrm{A}}$ is the piston side chamber area and $A_{\mathrm{B}}$ is the piston rod side chamber area. The absolute values of the pressure 
drops across the control valves follow the square root model of a turbulent orifice:

$$
\left|\Delta p_{A}\right|=\left(\frac{Q_{A}}{K_{V}}\right)^{2} ; \quad\left|\Delta p_{B}\right|=\left(\frac{Q_{B}}{K_{V}}\right)^{2}
$$

where $K_{\mathrm{V}}$ is the sum of flow coefficients of the two parallel connected on/off-valves. The force of the actuator is therefore:

$$
F=\left\{\begin{array}{l}
\left(\boldsymbol{p}_{\boldsymbol{S}}\left(i_{A}\right)-\left|\Delta p_{A}\right|\right) A_{A}-\left(\boldsymbol{p}_{\boldsymbol{S}}\left(i_{B}\right)+\left|\Delta p_{B}\right|\right) A_{B}, v_{r e f} \geq 0 \\
\left(\boldsymbol{p}_{\boldsymbol{S}}\left(i_{A}\right)+\left|\Delta p_{A}\right|\right) A_{A}-\left(\boldsymbol{p}_{\boldsymbol{S}}\left(i_{B}\right)-\left|\Delta p_{B}\right|\right) A_{B}, v_{r e f}<0
\end{array}\right.
$$

where $p_{\mathrm{S}}\left(i_{\mathrm{A}}\right)$ is the pressure level of the $i_{\mathrm{A}}^{\text {th }}$ pressure source.

Figure 3 presents the possible forces produced by $\varnothing 80 / 40$ actuator as a function of the piston velocity. The supply pressure $p_{\mathrm{HP}}$ is set to $15 \mathrm{MPa}$ and the return line pressure $p_{\mathrm{LP}}$ to $1 \mathrm{MPa}$. The area ratios of the four converter cylinders are $\boldsymbol{R}=\left[\begin{array}{llll}2.78 & 2.08 & 1.56 & 1.24\end{array}\right]$ and the cylinder sizes $\varnothing 50 / 40$, $\varnothing 50 / 36$, Ø 50/30 and $\varnothing 50 / 22$ as in the experimental test system presented in section 3.1. The six supply pressure alternatives are thus

$$
\boldsymbol{p}_{\boldsymbol{S}}=\left[p_{L P} \frac{p_{H P}}{\boldsymbol{R}(1)} \frac{p_{H P}}{\boldsymbol{R}(2)} \frac{p_{H P}}{\boldsymbol{R}(3)} \frac{p_{H P}}{\boldsymbol{R}(4)} p_{H P}\right]
$$

The nominal flow of the two parallel connected on/off-valves are according to the manufacturer data sheet approximately $Q_{\mathrm{N}}=251 / \mathrm{min}$ at $\Delta p_{\mathrm{N}}=0.5 \mathrm{MPa}$ [15]. The flow coefficient is

$$
K_{V}=\frac{Q_{N}}{\sqrt{\Delta p_{N}}}
$$

Figure 3 shows the $N_{\mathrm{p}}^{2}=36$ force levels generated by the different valve control combinations.

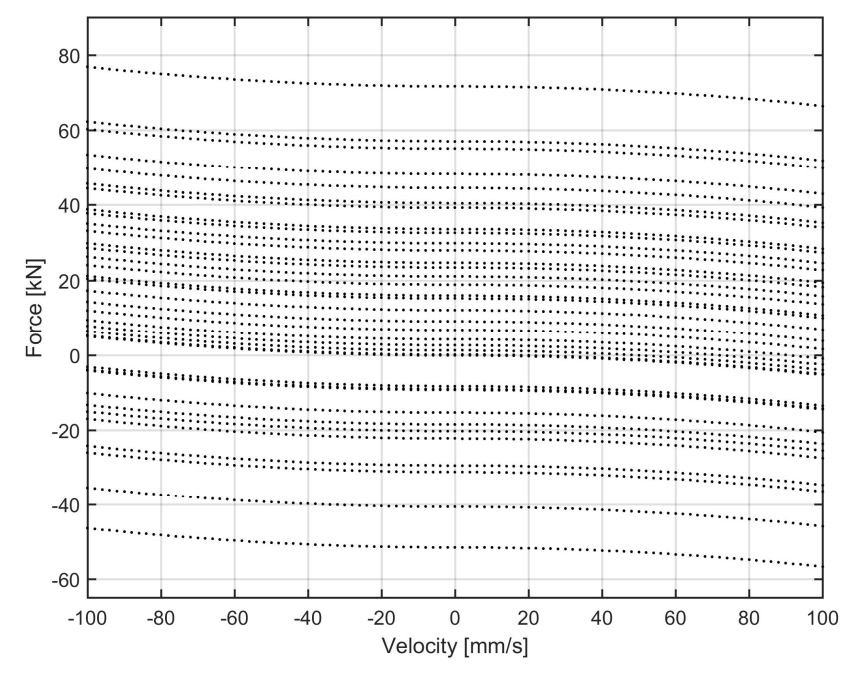

Figure 3: Possible actuator forces

The force levels generated are not evenly spaced between the minimum and maximum force. The force resolution is very coarse outside the range -31 to $57 \mathrm{kN}$, when zero velocity region is studied. Also inside this force range there are relatively big step sizes found especially just below $0 \mathrm{kN}$ at zero velocity. When velocity differs from zero, the pressure drops of the on/off-valves shift the force series depending on the movement direction and absolute value of the velocity. However, it is worth to note that the force control step sizes remain independent of the velocity.

\subsection{PNM-controller}

In order to increase the resolution, the two parallel connected on/off-valves can be controlled separately. The valves are similar sized and therefore pulse number modulation (PNM) control is the selected control mode. Flow path from the pressure supply to the cylinder chamber may be controlled by opening zero, one or two parallel on/off-valves. Thus the control matrix defining the possible valve control candidates for a single cylinder chamber is:

$$
\boldsymbol{u}_{\boldsymbol{P N M}}=\left[\begin{array}{llllllllllll}
1 & 2 & 0 & 0 & 0 & 0 & 0 & 0 & 0 & 0 & 0 & 0 \\
0 & 0 & 1 & 2 & 0 & 0 & 0 & 0 & 0 & 0 & 0 & 0 \\
0 & 0 & 0 & 0 & 1 & 2 & 0 & 0 & 0 & 0 & 0 & 0 \\
0 & 0 & 0 & 0 & 0 & 0 & 1 & 2 & 0 & 0 & 0 & 0 \\
0 & 0 & 0 & 0 & 0 & 0 & 0 & 0 & 1 & 2 & 0 & 0 \\
0 & 0 & 0 & 0 & 0 & 0 & 0 & 0 & 0 & 0 & 1 & 2
\end{array}\right]
$$

where the six rows represent the six pressure sources, the columns the different control candidates and the numbers correspond to the number of opened valves.

By opening a single valve, the pressure drop $\Delta p_{\mathrm{A}}$ or $\Delta p_{\mathrm{B}}$ can be increased to generate additional unique force levels at the cost of the energy efficiency. The number of control alternatives is now $\left(N_{\text {valves }} \cdot N_{\mathrm{p}}\right)^{2}=144$, where $N_{\text {valves }}$ is the number of valves in each flow path. The possible forces are presented in fig. 4 . The possible flow coefficients of the flow paths are now 2.95.10-7 $\mathrm{m}^{3} /\left(\mathrm{s} \mathrm{Pa}^{1 / 2}\right)$ and $5.89 \cdot 10^{-7} \mathrm{~m}^{3} /\left(\mathrm{s} \mathrm{Pa}^{1 / 2}\right)$ depending on the number of opened valves. The opening of a single valve only generates excessive pressure drop at higher velocities leading to very high or low chamber pressures. Therefore, those control candidates, which produce chamber pressures exceeding the limits $p_{\max }=25 \mathrm{MPa}$ or $p_{\min }=0 \mathrm{MPa}$ or generate more than $2 \mathrm{~kW}$ power loss, are disregarded.

The force resolution is greatly improved, when velocity is outside the range $-30 \ldots 30 \mathrm{~mm} / \mathrm{s}$. At smaller velocities, the flow rates do not generate significant pressure drop across the control edge even if only a single valve is opened. Therefore, the use of two-valve PNM-control does not solve all problems related to the controllability. Furthermore, the most accurate control is typically desired at slow velocity movements. However, the velocity range, where the PNM-control is effective, can be altered by increasing the number of the parallel valves and by modifying the flow capacity of the valves. In order to extend the fine resolution range closer to zero velocity, the valve flow coefficients can be selected e.g. $1 / 4 \& 3 / 4$ instead of the $1 / 2 \& 1 / 2$ ratio presented. However, in that case the pressure drop of the smaller valve becomes excessive at relatively low velocities limiting the usable fine force resolution to narrow velocity range. 


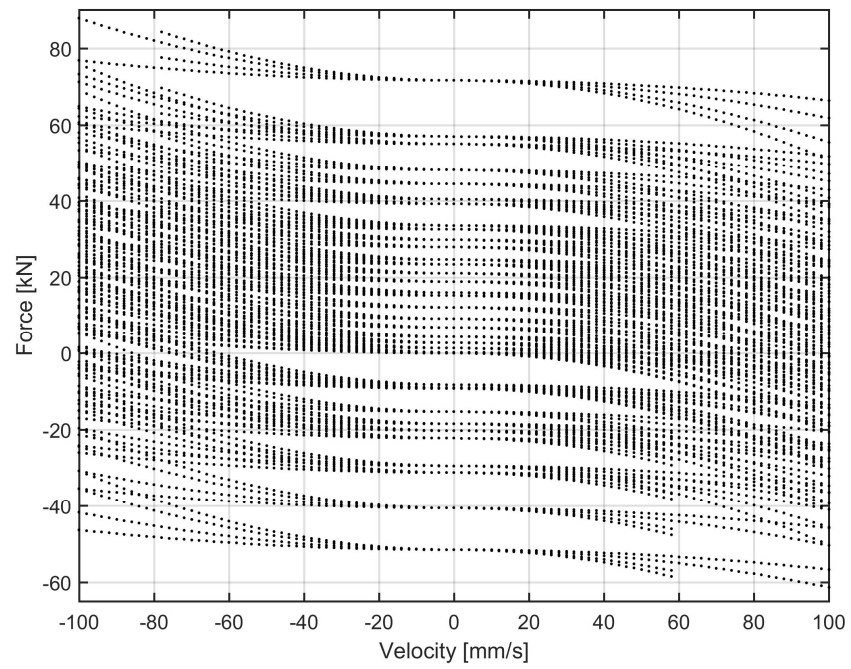

Figure 4: Possible actuator forces when 2-bit PNM-control is enabled

\subsection{Controller enabling crossflow-connection}

Improving the velocity range close to zero velocity is difficult by using PNM-control. Crossflow from a pressure supply to another pressure supply through a cylinder chamber is a viable method to increase the force resolution even if the net flow rate to the cylinder chamber is zero or small. The idea is to open e.g. a single control valve of the flow path P4¥ A and another valve of the flow path $\mathrm{P} 3 \ddagger \mathrm{A}$. In the equilibrium, the flow rates satisfy:

$$
\boldsymbol{Q}_{\boldsymbol{S}}(4)=v_{r e f} A_{A}-\boldsymbol{Q}_{\boldsymbol{S}}(3)
$$

where the positive flow rate $Q_{\mathrm{S}}$ is from the pressure supply to the cylinder chamber. The chamber pressure $p_{\mathrm{A}}$ depends on the supply pressures, piston velocity and the flow coefficients of the two flow paths. In the equilibrium, following equation holds:

$$
K_{V 4} \sqrt[*]{\boldsymbol{p}_{\boldsymbol{S}}(4)-p_{A}}=v_{r e f} A_{A}-K_{V 3} \sqrt[*]{\boldsymbol{p}_{\boldsymbol{S}}(3)-p_{A}}
$$

where $\sqrt[*]{x}=\operatorname{sign}(x) \sqrt{|x|}$. Bisection method is utilized to find the equilibrium chamber pressure $p_{\mathrm{A}}$ satisfying the condition.

In order to limit the flow rate between the converter cylinders and thus the power loss, only two adjacent supply pressure levels are used in crossflow connection. Furthermore, control candidates where both flow paths are activated by opening two valves are disregarded. Therefore, only following valve control combinations are allowed to generate the crossflow connection:

$$
\boldsymbol{u}_{\text {crssflw }}=\left[\begin{array}{lllllllllllllll}
1 & 2 & 1 & 0 & 0 & 0 & 0 & 0 & 0 & 0 & 0 & 0 & 0 & 0 & 0 \\
1 & 1 & 2 & 1 & 2 & 1 & 0 & 0 & 0 & 0 & 0 & 0 & 0 & 0 & 0 \\
0 & 0 & 0 & 1 & 1 & 2 & 1 & 2 & 1 & 0 & 0 & 0 & 0 & 0 & 0 \\
0 & 0 & 0 & 0 & 0 & 0 & 1 & 1 & 2 & 1 & 2 & 1 & 0 & 0 & 0 \\
0 & 0 & 0 & 0 & 0 & 0 & 0 & 0 & 0 & 1 & 1 & 2 & 1 & 2 & 1 \\
0 & 0 & 0 & 0 & 0 & 0 & 0 & 0 & 0 & 0 & 0 & 0 & 1 & 1 & 2
\end{array}\right]
$$

If both control candidates of the PNM-control matrix $\boldsymbol{u}_{\mathrm{PNM}}$ and the crossflow-control matrix $\boldsymbol{u}_{\text {crssflw }}$ are considered, all the force levels presented in fig. 5 are possible. Again, all control candidates producing chamber pressures exceeding the allowed range or producing more than $2 \mathrm{~kW}$ of power loss are disregarded. The number of control candidates is now $\left(2 \cdot N_{\mathrm{p}}+3 \cdot\left(N_{\mathrm{p}-1}\right)\right)^{2}=729$ for the system with two parallel valves in each flow path and the limitations concerning the crossflow mentioned.

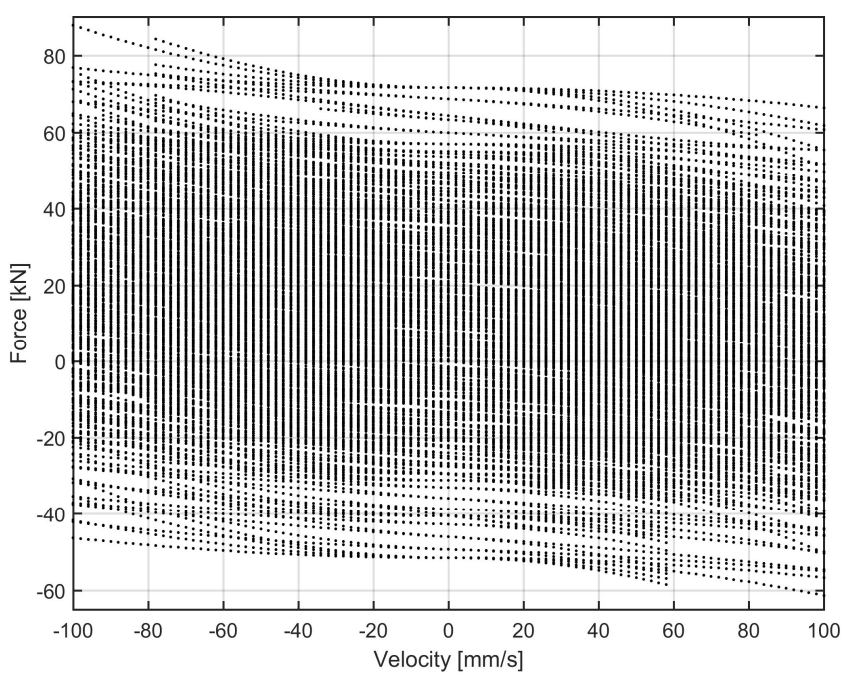

Figure 5: Possible actuator forces when PNM-control and crossflow connection are enabled

\subsection{Summary}

Figure 6 presents a summary of the control resolution. The three different types of controller are compared in the figure. The sum of squared force step sizes is given as a function of the actuator velocity. The figure clearly shows, that although the 2-bit PNM-control method improves the controllability significantly at higher velocities, the improvement is negligible at smallest velocities, where typically the fine control resolution is desired.

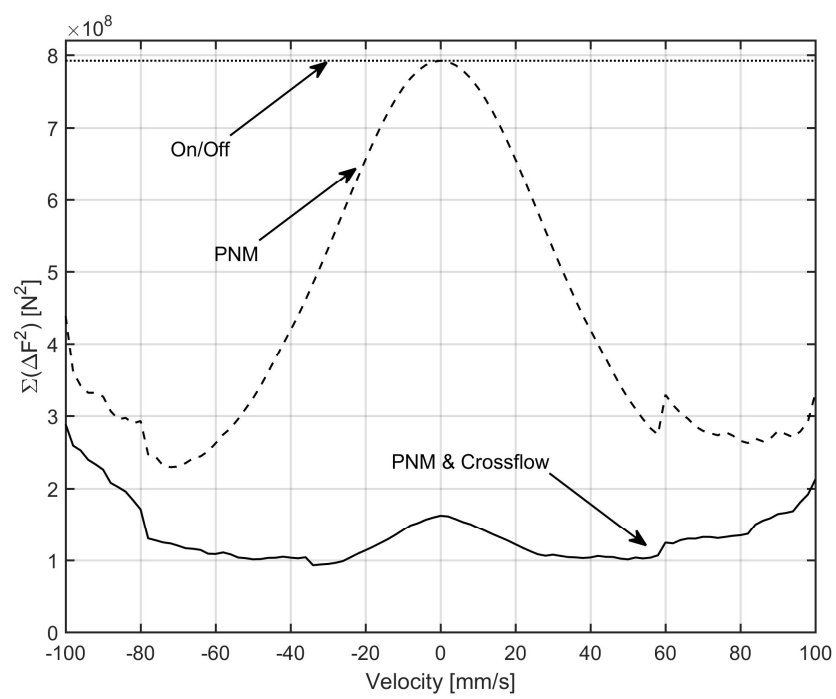

Figure 6: Sum of squared force step sizes (power loss of $2 \mathrm{~kW}$ is allowed)

The controller enabling crossflow-connection can significantly improve the controllability at slow velocities. 
Figure 7 presents similar summary of the force resolution, when the allowed power loss is limited to $1 \mathrm{~kW}$. The use of crossflow connection is drastically decreased. However, still the force resolution near zero velocity is significantly improved when compared to the On/Off-type control.

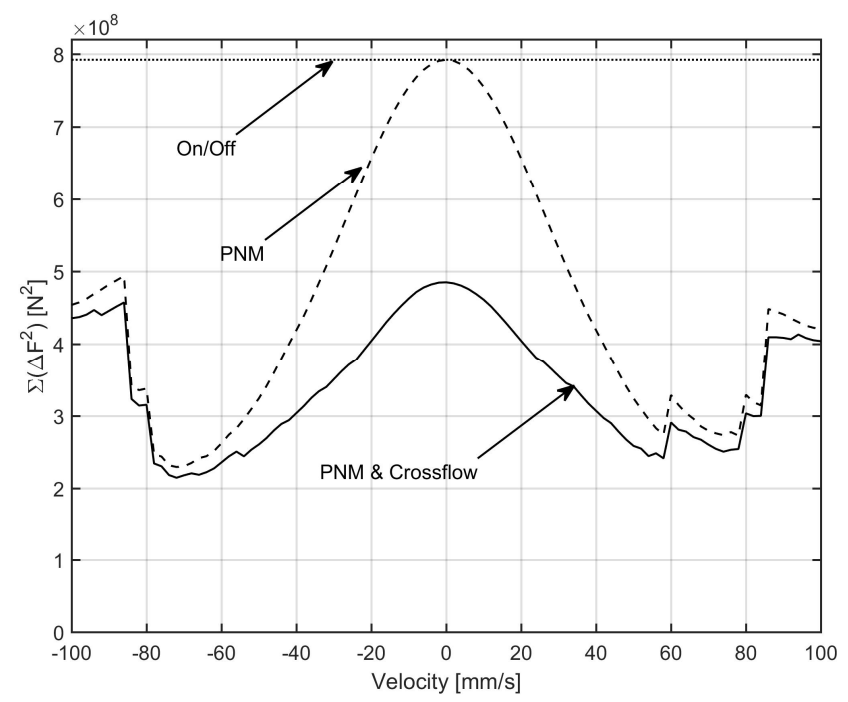

Figure 7: Sum of squared force step sizes (power loss of $1 \mathrm{~kW}$ is allowed)

\section{Experimental study}

The controllability of the actuator concept is studied experimentally in a mobile boom mock-up. Furthermore, the energy efficiency is compared to previously measured energy efficiency of load sensing mobile proportional valve based system [16] and four-chamber cylinder based system [13]. The sources of the partial power losses are studied using separate measurements.

\subsection{Measurement system}

The measurement system is based on a four-meter-long boom mock-up (detailed dimensions of the boom can be found in [10]). The hybrid actuator concept is equipped with a number of pressure and position sensors as presented in fig. 8. There are also flow sensors connected to the supply line and the return line in order to measure the input power. Small fixed displacement pump with a start/stop logic delivers the hydraulic input power and the supply pressure reference is set to $15 \mathrm{MPa}$. In addition to the diagram presented, there are pressure relief valves in supply line and the actuator lines for safety reasons.

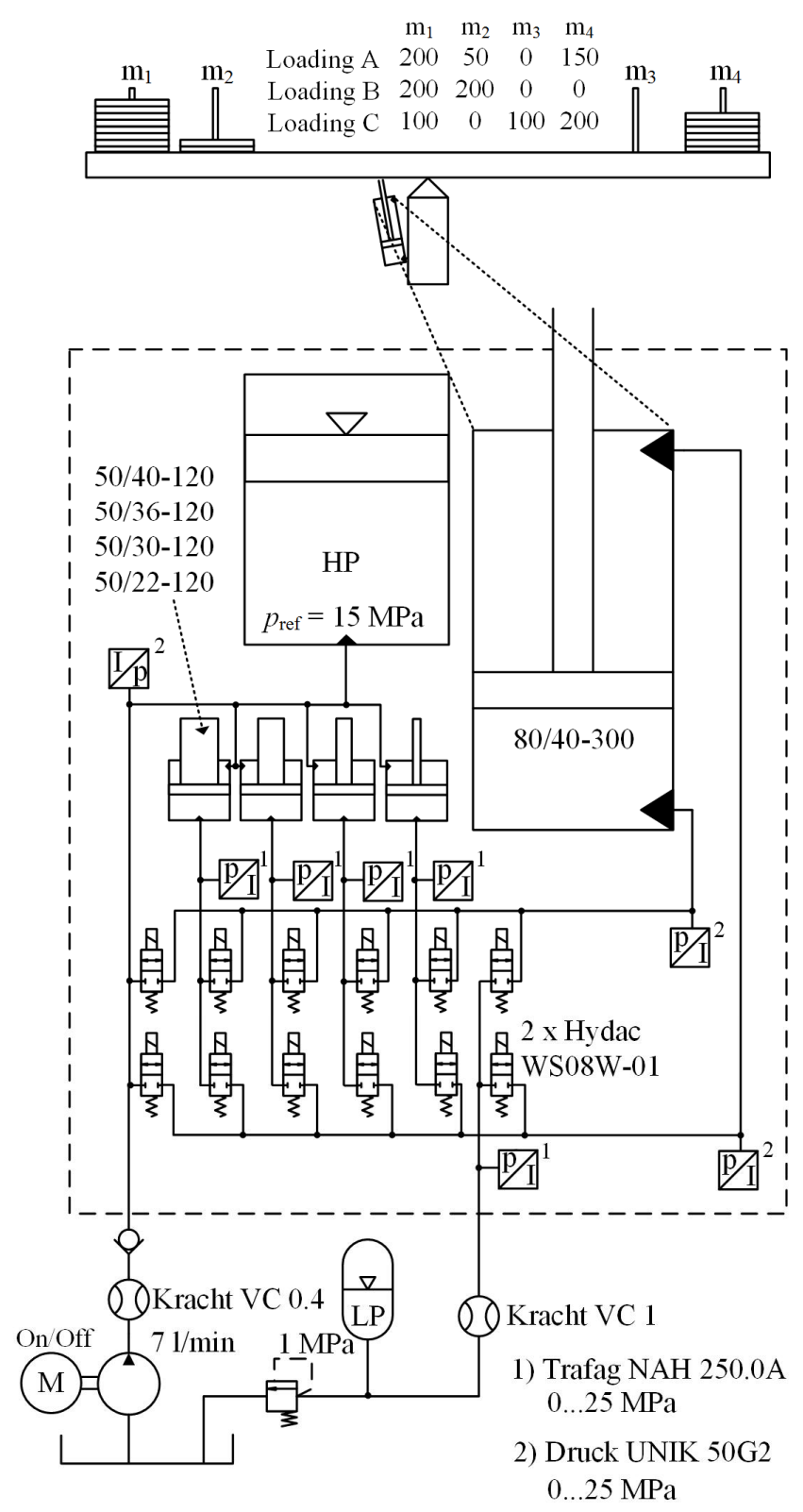

Figure 8: Experimental test setup and the three different loadings measured $(\mathrm{kg})$.

\subsection{Measurement results}

The measurements are performed to study the energy efficiency and controllability of the system. The energy efficiency of the system is investigated using a special smooth position trajectory, which has been previously utilized while studying different types of digital hydraulic systems and load sensing proportional valve based system [16]. The control resolution of the three different controller types is studied using a modified position trajectory, where the velocities are halved and the movement times doubled such that identical piston strokes are driven. 


\subsubsection{Controllability}

The controllability of large inertia load during high velocity movements is relatively good even with the basic controller and the actuator concept enables fast response due to small capacitances and fast on/off-valves. However, the control resolution at slow velocities requires improvement to enable smooth velocity tracking, accurate positioning and to avoid oscillations during stopping of the movement as seen in fig. 9. All measured trajectories presented are measured with the loading B.
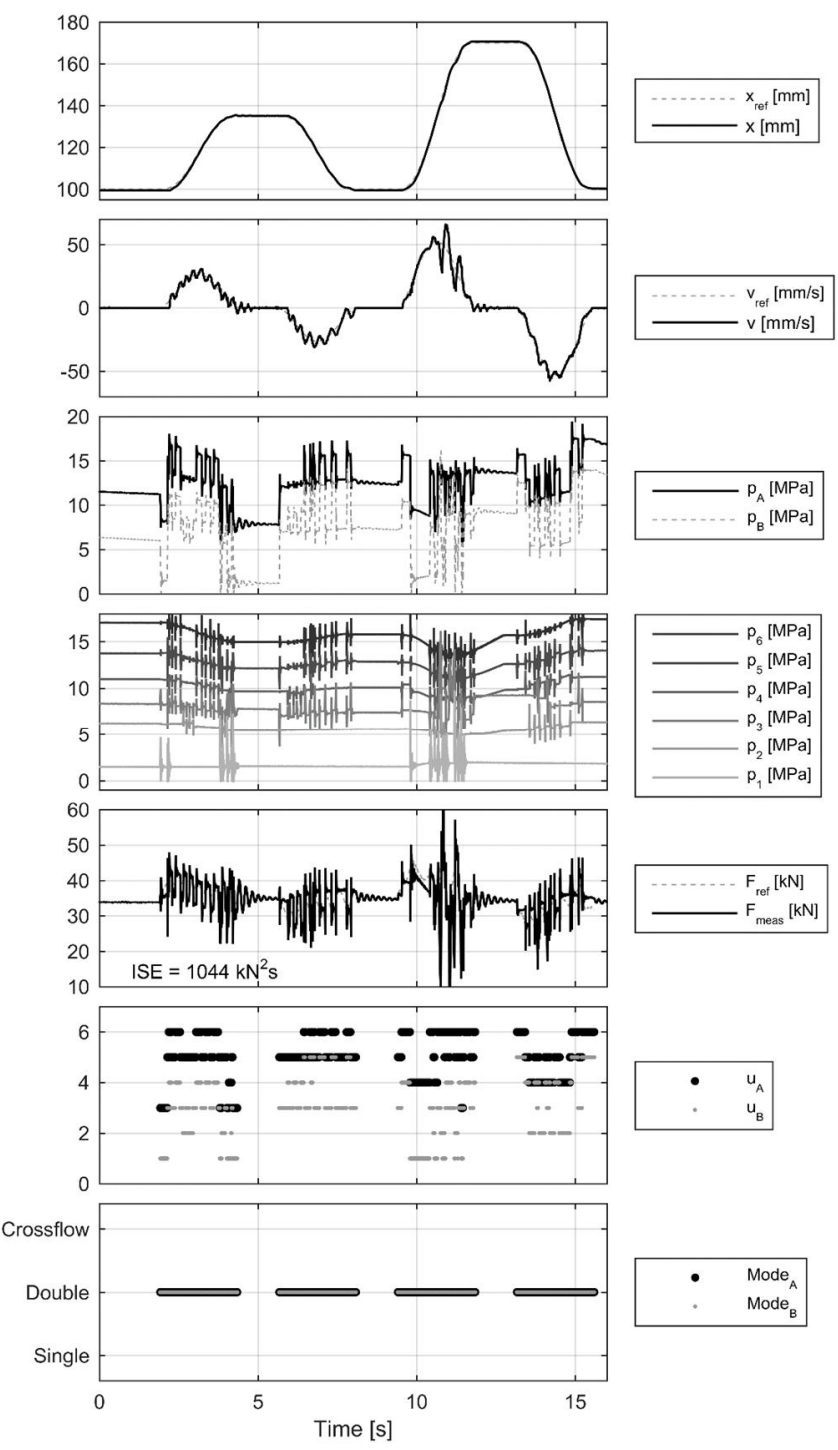

Figure 9: Measured slow velocity trajectory with basic controller

Figure 9 includes measured position and velocity together with their reference values in the two topmost diagrams. The piston side chamber pressure $p_{\mathrm{A}}$, the rod side chamber pressure $p_{\mathrm{B}}$ and the supply pressures $p_{1} \ldots p_{6}$ are given in the middle. The third lowest diagram presents the force reference generated by the motion controller as well as the actual force calculated from the measured chamber pressures. Furthermore, the integral square error (ISE) of the force control is given. The ISE value is calculated based on the complete measurement including five repetitions of the trajectory shown. The two lowest diagrams relate to the valve command signal for piston side and rod side on/off-valves. The lowest diagram shows whether a single valve is opened (Single) or both parallel-connected valves (Double) are opened between cylinder chamber and the pressure source. The third option is that the cylinder chamber is connected to two pressure sources (Crossflow). The second lowest diagram shows which pressure sources are connected to the cylinder chambers $(1=\mathrm{LP} \ldots 6=\mathrm{HP})$.

The force control resolution is coarse resulting in considerable velocity error and relatively high accelerations despite the smooth velocity reference. Due to coarse resolution, the amplitude of the measured oscillations in supply pressures and chamber pressures is high. The controllability can be improved by introducing PNM-control as presented in fig. 10 .
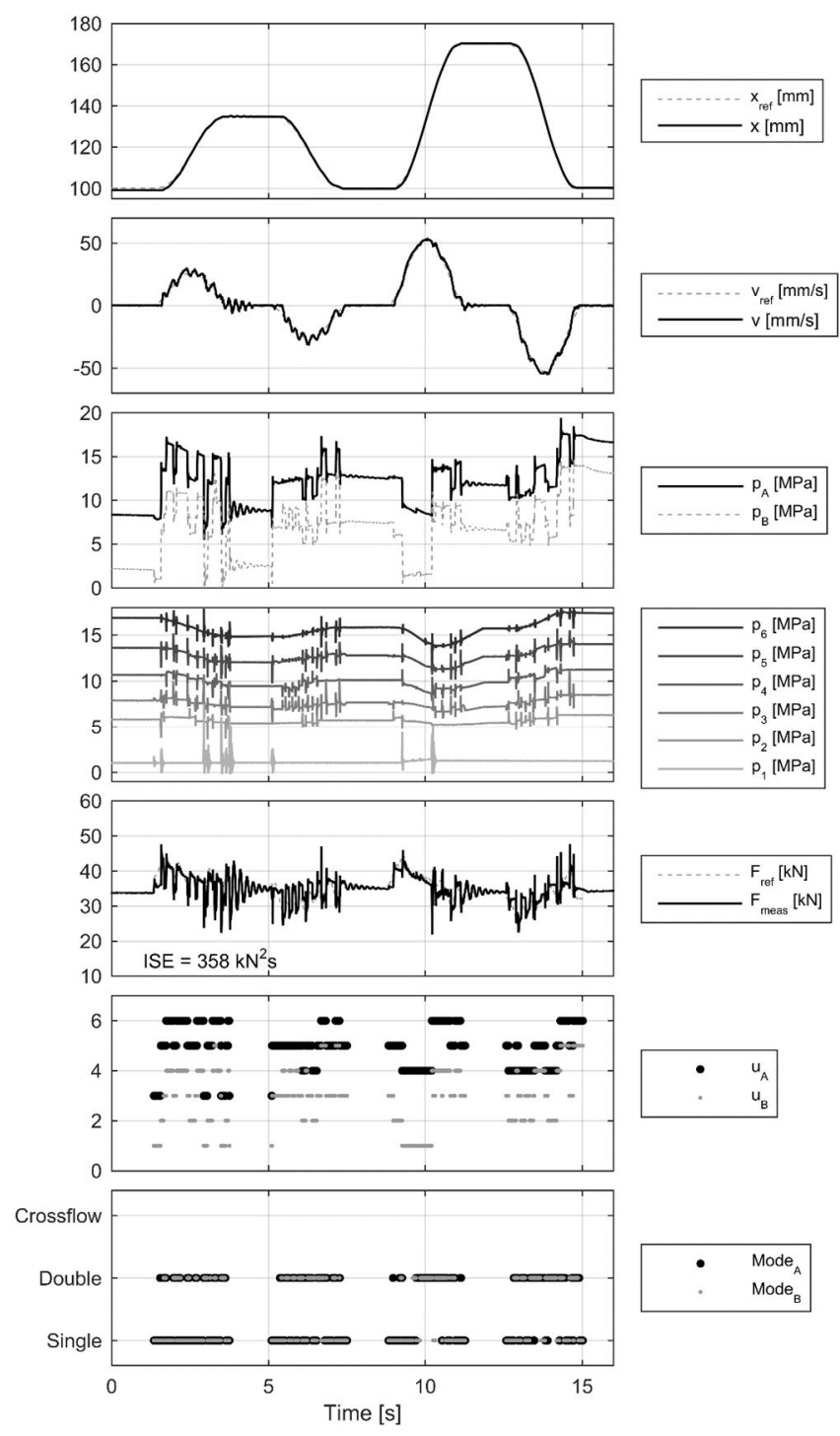

Figure 10: Measured slow velocity trajectory with PNMcontrol enabled

As the numerical study in section 2 shows, the two-valve PNM-control is capable of improving the control resolution 
at certain velocity range. In this case, the resolution is not improved when the movement velocity is close to zero. Thus, the smoothness of the smaller movement having a peak velocity of $26 \mathrm{~mm} / \mathrm{s}$ is not significantly improved. However, the pressure oscillations are suppressed compared to the measurement carried out with the basic controller. In addition, the smoothness of the velocity tracking is improved during the larger movement having a peak velocity of $53 \mathrm{~mm} / \mathrm{s}$. Force tracking result is improved as the significant change in the ISE value demonstrates. The third controller type enables also the crossflow connection and thus the best resolution of the controller types tested. The measurement results of the controller type are presented in fig. 11.
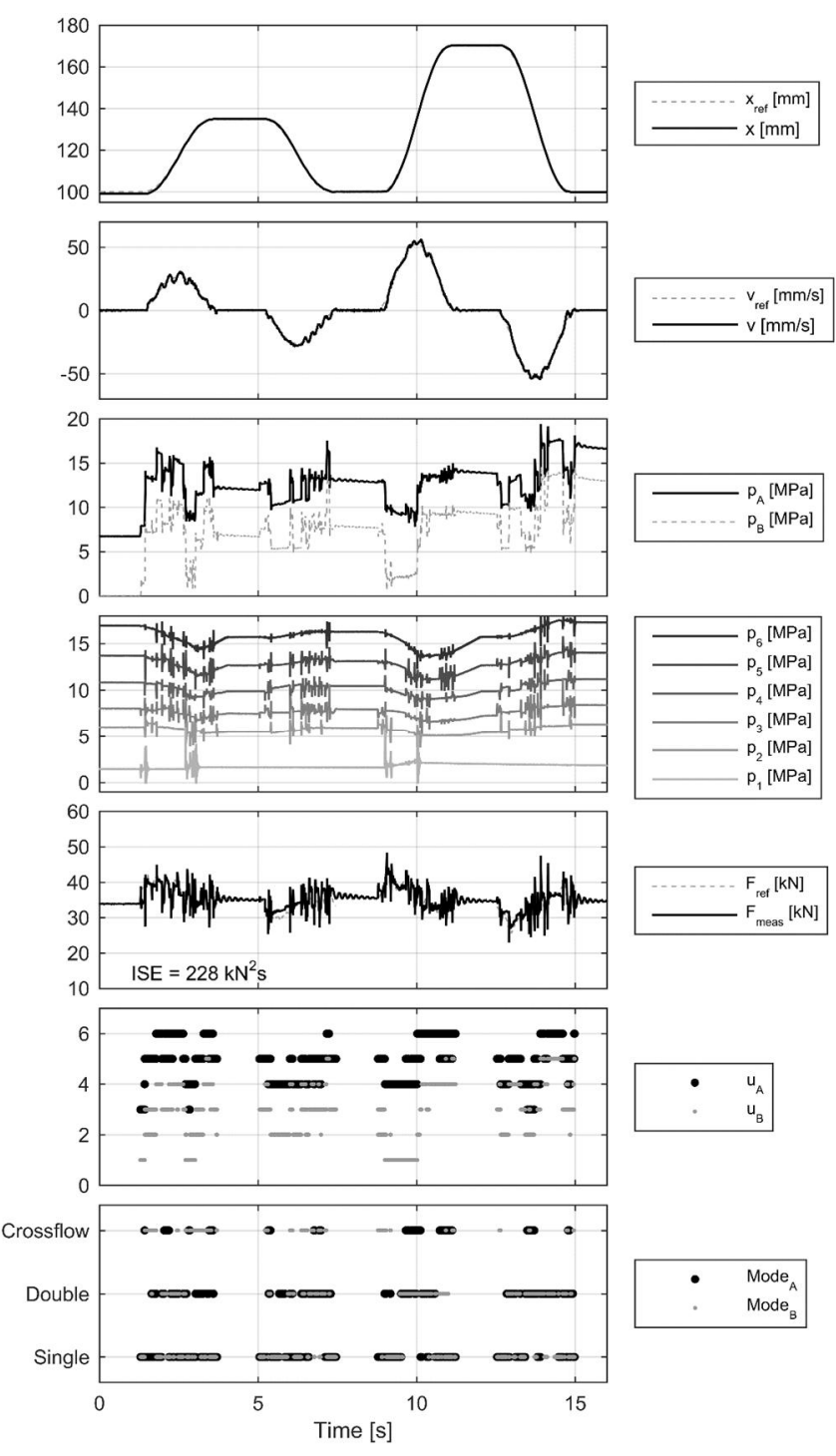

Figure 11: Measured slow velocity trajectory with PNMcontrol \& crossflow enabled

The crossflow connection enables improvement on force control resolution also during slow velocity movements. However, the measured response shows that even with the PNM-control and the crossflow connection enabled, there are small velocity oscillations still present. Nevertheless, by enabling the PNM-control and the crossflow connection, the velocity error and oscillations are decreased when compared to the simpler controllers and the ISE value of the force tracking is considerably improved.

\subsubsection{Energy efficiency}

Figure 12 presents part of the measured faster trajectory tracking result using PNM-control and crossflow connection. The total output energy of the movement includes only piston friction and small flow losses. The input energy is measured from the hydraulic supply line and pressurized tank line using the pressure and flow sensors. The trajectory shown is repeated five times during a single measurement. The measurement is then repeated five times thus leading to 25 repetitions of the trajectory. The average energy loss of a single trajectory (PNM \& Crossflow; loading B) is $2.9 \mathrm{~kJ}$ if the energy returned to the pressurized tank line is not lost but can be utilized.

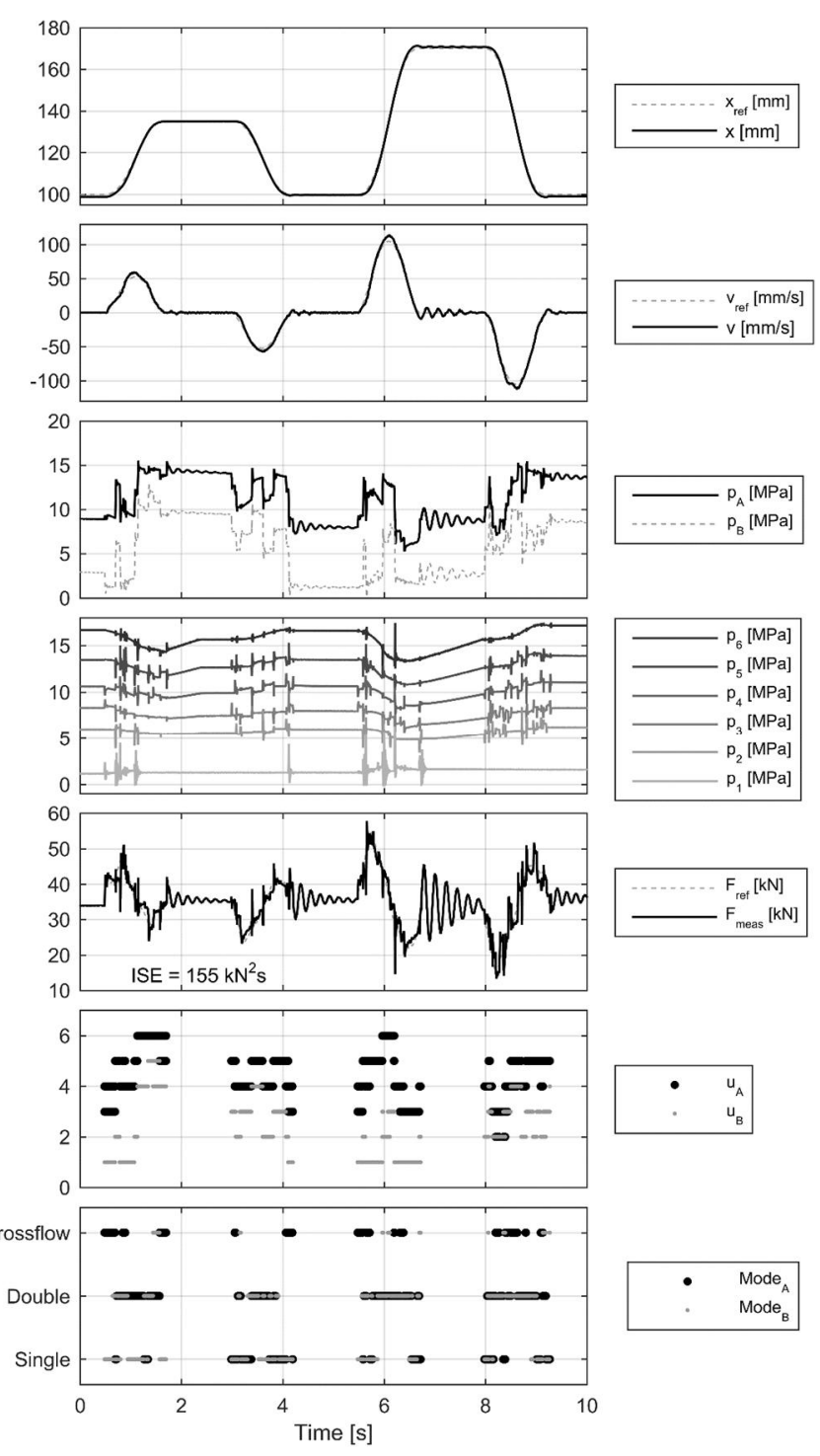

Figure 12: Measured fast velocity trajectory with PNMcontrol and crossflow enabled

The average energy losses of the three loadings driven with the different control methods are given in tab. 1 . The energy losses are scaled according to the total movement distance of 
the piston $(210 \mathrm{~mm})$ to enable a comparison with different kind of trajectories.

Table 1: Average energy loss / movement distance [J/mm] in fast velocity trajectory

\begin{tabular}{llll}
\hline & Load A & Load B & Load C \\
\hline Basic & 10.2 & 10.9 & 10.9 \\
\hline PNM & 9.9 & 11.3 & 9.9 \\
\hline PNM \& Crossflow & 12.7 & 13.6 & 14.1
\end{tabular}

Figure 13 compares the average energy losses of a single trajectory to previously measured results with load sensing proportional valve based system [16] and secondary controlled four-chamber system [13]. The proportional valve used in the reference measurements was a Bosch Rexroth M4-12 and the load sensing pressure margin was set to 1.0 MPa. The results concerning energy efficiency of the concept are remarkable: the new concept can avoid up to $77 \%$ of the losses generated by the proportional valve based system depending on the controller type used.

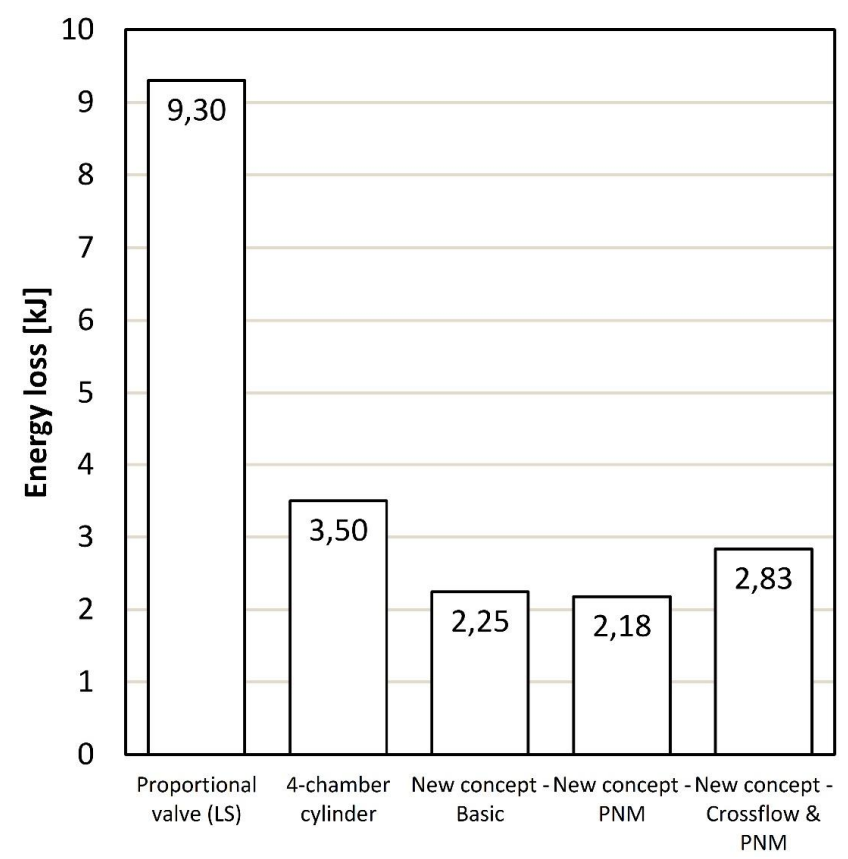

Figure 13: Comparison of measured energy losses in fast velocity trajectory

Even though the new concept increases the energy efficiency considerably, there are still significant energy losses present. To find the reasons for these losses, partial power losses of the system are studied next.

\subsubsection{Sources of energy losses}

Figure 14 presents an example of the partial power losses in the actuator concept. The total power loss of the system is formed by the pressure drop in the on/off-valves, flow losses in the piping, cylinder friction, thermodynamic energy losses in the accumulator and losses related to the pressurization and de-pressurization of the actuator chambers.
The figure presents following partial power losses:

- Pressure loss of the on/off-valve

- $\quad$ Pressure loss of the pipe between converter cylinder and the valve block

- Friction loss of the converter cylinder \& pressure loss in the cylinder fittings

- Pressure loss of the pipe between high pressure accumulator and converter cylinder

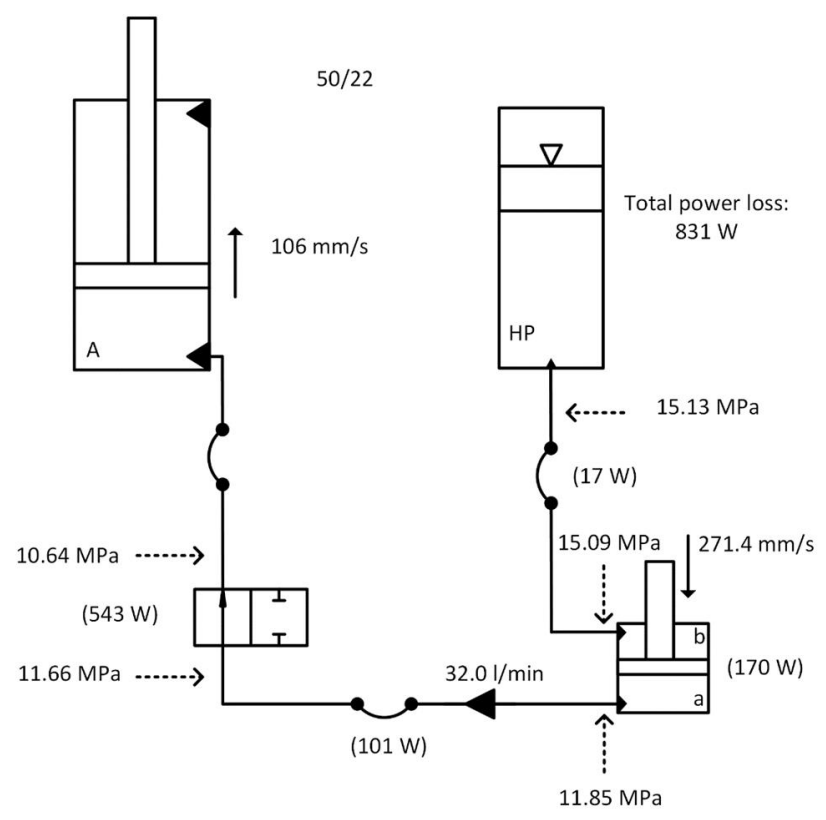

Figure 14: Power loss of the converter circuit at maximum velocity

The flow rate on both sides of the converter cylinder is estimated from the position measurement of the actuator. The flow rates are approximated from the derived velocity and cylinder areas. The velocity and pressure readings are examined, when the velocity is constant and the pressure fluctuations induced by the valve activity are settled. $32 \mathrm{l} / \mathrm{min}$ flow rate is the maximum designed flow rate of the system enabling roughly $0.1 \mathrm{~m} / \mathrm{s}$ maximum velocity of the actuator. The pressure drop of the logic valve induces majority of the power loss in the circuit. The flow through the valve is turbulent and thus the power losses decrease rapidly as the flow rate is decreased: halving the flow rate decreases the valve power loss to $1 / 8$.

Figure 15 presents the summary of the power losses in each converter cylinder circuit when maximum velocity is driven and the converter cylinder is connected to actuator piston-side chamber. All converter cylinders are measured with flow rate $32.0 \mathrm{l} / \mathrm{min}$, except for cylinder $50 / 30$ where the flow rate is approximately $2 \%$ higher: $32.6 \mathrm{l} / \mathrm{min}$.

When average values of the four converter cylinders are considered, the on/off-valve generates $66 \%$, the medium pressure line generates $12 \%$, the cylinder friction generates $21 \%$ and the accumulator line generates $1 \%$ of the total power loss. The power loss of the accumulator line clearly depends on the converter area ratio, but its effect on the total power loss is negligible. The friction loss of the converter 
cylinder together with pressure drop occurring in the cylinder ports and fittings is relatively small.

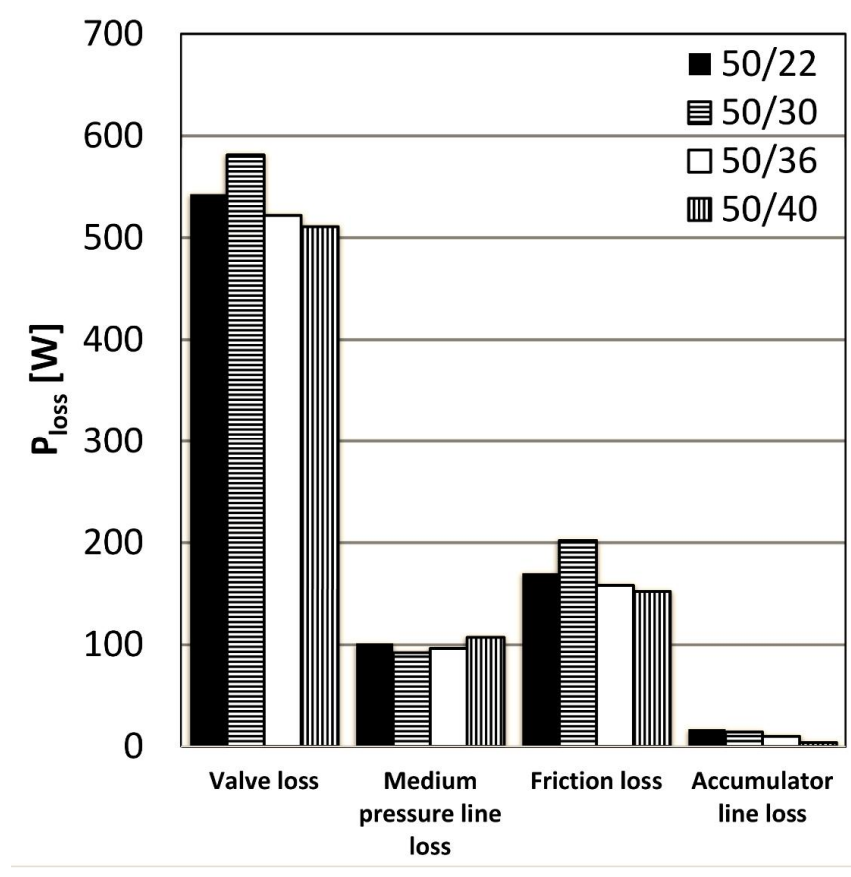

Figure 15: Measured partial power losses of the converter cylinder circuits

\section{Discussion and conclusions}

The paper presents an experimental study of a new digital hydraulic multi-pressure actuator. The energy efficiency of the concept is high compared to traditional four-way load sensing proportional valve based system. The measurements show up to $77 \%$ reduction in energy losses. Furthermore, the measurement results show that the single biggest remaining source of power loss in the concept is the on/off-valve at least at high velocities.

Three different controller types are studied in the paper. The first type is a simple on/off-type controller, where each flow path is either fully open or closed. The second type called pulse number modulation takes advantage of the fact that there are two parallel-connected on/off-valves in each flow path. The pulse number modulation enables independent control of the two valves thus allowing adjustment of the pressure drop across the flow path. The third controller type enables crossflow from a pressure supply to another thus allowing the generation of chamber pressures between the discrete supply pressure levels. The use of pulse number modulation and crossflow connection improves the control resolution significantly as the numerical and experimental results show. However, the use of crossflow connection adds power losses considerably and thus the excessive use of the connection should be avoided.

The controllability of the new concept compared to load sensing proportional valve is twofold: the dynamics of the control system are fast due to the control type and fast on/offvalves leading to e.g. small position tracking error; on the other hand, there are small amplitude oscillations present during slow velocity movements indicating slightly limited resolution. If needed, the controllability can be further improved by e.g. increasing the number of parallel valves. The new concept enables considerably higher efficiency when compared to proportional valve based load sensing systems, which are common in commercial mobile machine applications. Furthermore, the concept enables the decoupling of input and output power. As the generation and utilization of the power are decoupled, the prime mover of the mobile machine can be driven against constant or slowly varying loading. Furthermore, the prime mover, which is usually a Diesel engine at the moment of writing, can be driven in efficient operating range.

The results presented were obtained with a proof-of-concept prototype, where the system was built based on separate standard components. As such, the cost of the new actuator concept is considerably higher than e.g. traditional actuator driven by a load sensing valve. On the other hand, the new concept enables certain amount of cost reduction on system level, where a smaller constant displacement pump can be utilized in place of the variable displacement unit. Whether the increased manufacturing costs are justified by the decreased fuel costs, depends heavily on the application type and its load cycle.

\section{Acknowledgement}

The research was funded by Academy of Finland (Grant No. 278464).

\section{References}

[1] M Lindgren, and P-A Hansson. Effect of Transient Conditions on Exhaust Emission from two Non-road Diesel Engines. Biosystems Engineering, Vol 87, Issue 1, 2004.

[2] M Vukovic, R Leifeld and H Murrenhoff. STEAM - a hydraulic hybrid architecture for excavators. Proc. of $10^{\text {th }}$ International Fluid Power Conference. 8-10 March, 2016, Dresden, Germany.

[3] K Schneider. Liebherr Pactronic ${ }^{\circledR}$ - Hybrid Power Booster, Energy Recovery and Increased Performance with Hybrid Power. Proc. of $8^{\text {th }}$ International Fluid Power Conference. 26-28 March, 2012, Dresden, Germany.

[4] K Einola and A Kivi. First Experimental Results of a Hydraulic Hybrid Concept System for a Cut-to-Length Forest Harvester. Proc. of $14^{\text {th }}$ Scandinavian International Conference on Fluid Power. 20-22 May, 2015, Tampere, Finland.

[5] P Achten and T van den Brink. A hydraulic transformer with a swash block control around three axis of rotation. Proc. of 8th International Fluid Power Conference, 2628 March 2012, Dresden, Germany.

[6] H Kogler and R Scheidl. Energy Efficient Linear Drive Axis Using a Hydraulic Switching Converter. Journal of 
Dynamic Systems, Measurement and Control. 2016, Vol 138(9). doi: 10.1115/1.4033412.

[7] M Pan, J Robertson, N Johnston, A Plummer and A Hillis. Experimental investigation of a switched inertance hydraulic system. Proc. of ASME/Bath Symposium on Fluid Power and Motion Control 2014 (FPMC14). Bath, UK.

[8] C Williamson, J Zimmerman, and M Ivantysynova. Efficiency Study of an Excavator Hydraulic System Based on Displacement-Controlled Actuators. Proc of ASME/Bath Workshop on Fluid Power and Motion Control 2008 (FPMC08). Bath, UK.

[9] M Linjama, M Huova, M Pietola, J Juhala, and K Huhtala. Hydraulic Hybrid Actuator. Theoretical Aspects and Solution Alternatives. Proc. of The $14^{\text {th }}$ Scandinavian International Conference on Fluid Power, May 20-22, 2015, Tampere, Finland.

[10] M Huova, A Aalto, M Linjama, K Huhtala, T Lantela, and $M$ Pietola. Digital Hydraulic Multi-Pressure Actuator - the Concept, Simulation Study and First Experimental Results. International Journal of Fluid Power. $\quad$ http://dx.doi.org/10.1080/14399776.2017. 1302775 .

[11]E Bishop. Digital Hydraulic Transformer - Approaching Theoretical Perfection in Hydraulic Drive Efficiency. Proc. of The $11^{\text {th }}$ Scandinavian International Conference on Fluid Power, June 2-4, 2009, Linköping, Sweden.

[12]E Bishop. Linearization of Quantized Digital Hydraulic Transformer Output. Proc. of The Third Workshop on Digital Fluid Power, October, 13-14, Tampere, Finland.

[13] M Linjama, H-P Vihtanen, A Sipola, and M Vilenius. Secondary Controlled Multi-Chamber Hydraulic Cylinder. Proc. of The 11th Scandinavian International Conference on Fluid Power, June 2-4, 2009, Linköping, Sweden.

[14]A Harrison and D Stoten. Generalized Finite Difference Methods for Optimal Estimation of Derivatives in RealTime Control Problems. Proceedings of the Institution of Mechanical Engineers, Part I: Journal of Systems and Control Engineering 1995, Vol 209: 67-78.

[15]Hydac WS08W-01 datasheet. Available: www.hydac. com.br/wp-content/uploads/e5924_ws08w01.pdf. January $27^{\text {th }} 2017$.

[16] M Linjama, M Huova, P Boström, A Laamanen, L Siivonen, L Morel, M Walden and M Vilenius. Design and Implementation of Energy Saving Digital Hydraulic Control System. Proc. of The Tenth Scandinavian International Conference on Fluid Power, 2007, Tampere, Finland. 